\title{
Serum Thyrotropin Concentration in Children with Isolated Thyroid Nodules
}

\author{
Alessandro Mussa, MD, $\mathrm{PhD}^{1}$, Maria Carolina Salerno, $\mathrm{MD}^{2}$, Gianni Bona, $\mathrm{MD}^{3}$, Malgorzata Wasniewska, $\mathrm{MD}^{4}$, \\ Maria Segni, $\mathrm{MD}^{5}$, Alessandra Cassio, $\mathrm{MD}^{6}$, Maria Cristina Vigone, $\mathrm{MD}^{7}$, Roberto Gastaldi, $\mathrm{MD}^{8}$, Lorenzo lughetti, $\mathrm{MD}^{9}$, \\ Arianna Santanera, $\mathrm{MD}^{1}$, Donatella Capalbo, $\mathrm{MD}^{2}$, Patrizia Matarazzo, $\mathrm{MD}^{1}$, Filippo De Luca, $\mathrm{MD}^{4}$, \\ Giovanna Weber, $\mathrm{MD}^{7}$, and Andrea Corrias, $\mathrm{MD}^{1}$
}

Objective To investigate the correlation between serum thyroid-stimulating hormone (TSH) concentration and nodule nature in pediatric patients with thyroid nodules, with the aim of identifying a marker able to differentiate benign and malignant nodules.

Study design This was a retrospective analysis of serum TSH concentrations in a multicentric case series of 125 pediatric patients with benign and malignant thyroid nodules.

Results Of the 125 patients, 99 had benign thyroid nodules and 26 had differentiated thyroid cancer (24 papillary and 2 follicular). Final diagnosis was based on surgery in 57 cases and on a benign cytology plus clinical follow-up in 68 cases. Serum TSH concentration was significantly higher in patients with thyroid cancer compared with those with benign nodules $(3.23 \pm 1.59 \mathrm{mU} / \mathrm{L}$ vs $1.64 \pm 0.99 \mathrm{mU} / \mathrm{L} ; P<.001)$. Binary logistic regression analysis revealed that serum TSH was the sole predictor of malignancy $(P<.001)$. Dividing the patient cohort into 5 groups based on serum TSH quintiles (TSH cutoffs $0.40,1.00,1.50,1.80$, and $2.80 \mathrm{mU} / \mathrm{L}$ ), we observed that cancer prevalence increased in parallel with serum TSH $(P<.001)$, with respective rates of $0 \%, 4 \%, 16 \%, 32 \%$, and $52 \%$ in the 5 quintile groups. Conclusion Because cases with malignant nodules are most likely seen in the upper normal serum TSH range (ie, $>2.8$ $\mathrm{mU} / \mathrm{L}$ ), serum TSH concentration can serve as a predictor of thyroid cancer in pediatric patients with thyroid nodules and can inform the decision of when to submit patients to further investigation by cytology. (J Pediatr 2013;163:1465-70).

hyroid cell proliferation depends on thyrotropin (thyroid-stimulating hormone [TSH]), which is the main factor acting on thyroid tissue. Evidence suggests that TSH signaling may be implicated in differentiated thyroid cancer, in which malignant cells usually express TSH receptor. ${ }^{1}$ Overactivation and hyperfunction of the TSH receptor has been observed in differentiated thyroid cancer, whereas it is most often silenced in the undifferentiated form. ${ }^{2}$ Moreover, in animal models, induced TSH elevation leads to thyroid hyperstimulation, resulting in hyperplasia and increased cancer development rate. ${ }^{3-5}$

Clinical observations point to a correlation between thyroid cancer and serum TSH concentration. Several previous investigations of adults with thyroid nodules have shown that a TSH concentration in the upper end of the reference range is correlated with an increased likelihood of thyroid cancer; serum TSH concentrations are higher in patients with differentiated thyroid cancer compared with those with benign thyroid nodules. ${ }^{6}$ In addition, patients with nodular goiter have lower serum TSH concentrations and a lower frequency of papillary thyroid cancer when treated with levothyroxine. ${ }^{7}$ Moreover, levothyroxine administration at dosages that induce serum TSH suppression have been linked to a reduced risk of thyroid cancer recurrence and increased survival. ${ }^{8}$ Finally, levothyroxine treatment may interfere with growth and formation of nodules. ${ }^{8-12}$

Two systematic reviews examining the association between serum TSH concentrations and differentiated thyroid cancer in adults have been published. ${ }^{13,14}$ Thyroid nodules are very rare in the pediatric population, with an estimated prevalence of only $0.05 \%-1.8 \%,{ }^{15,16}$ and only 1 study to date has investigated this association in children. ${ }^{17}$ Furthermore, pediatric thyroid cancer appears to be unique, differing from the adult form in terms of epidemiology and natural history. Thyroid nodules are more often malignant in children than in adults $(20 \%-25 \%$ of cases vs $5 \%-10 \%),{ }^{18-22}$ and pediatric thyroid cancer is almost invariably well differentiated and thus likely to be TSH-dependent.

In the present study, we investigated the correlation between serum TSH concentration and cytotype/histotype of thyroid nodules in children, with the aim of identifying a biochemical marker of malignancy for use in clinical practice.

\footnotetext{
BMI Body mass index

FNAB Fine-needle aspiration biopsy

TSH Thyroid-stimulating hormone
}

From the ${ }^{1}$ Division of Pediatric Endocrinology,

Department of Pediatrics, University of Torino, Torino,

Italy; ${ }^{2}$ Department of Pediatrics, University Federico II of Naples, Naples, Italy; ${ }^{3}$ Division of Pediatrics, Department of Medical Sciences, University of Piemonte Orientale, Novara, Italy; ${ }^{4}$ Department of Pediatrics, University of Messina, Messina, Italy; ${ }^{5}$ Department of Pediatrics, 1 st Faculty, La Sapienza University, Rome, Italy;

${ }^{6}$ Department of Pediatrics, University of Bologna,

${ }^{6}$ Department of Pediatrics, University of Bologna,
Bologna, Italy; ${ }^{7}$ Department of Pediatrics, University of Milan, Milan, Italy; ${ }^{8}$ Department of Pediatrics, University of Genoa, Genoa, Italy; and ${ }^{9}$ Department of Pediatrics, University of Modena and Reggio Emilia, Modena and Reggio Emilia, Italy

All authors are members of the Study Group for Thyroid Diseases of Italian Society for Pediatric Endocrinology and Diabetology (SIEDP/ISPED).

The authors declare no conflicts of interest.

0022-3476/\$ - see front matter. Copyright $\odot 2013$ Mosby Inc. All rights reserved. http://dx.doi.org/10.1016/j.jpeds.2013.07.003 


\section{Methods}

In this multicenter retrospective study of 125 patients with thyroid nodules diagnosed in childhood or adolescence, data were collected from a series of consecutive cases diagnosed and followed-up between 2006 and 2012 in 9 centers in the Study Group for Thyroid Diseases of the Italian Society for Pediatric Endocrinology and Diabetology. All of the clinicians involved were pediatric endocrinologists working in clinics dedicated to the diagnosis and treatment of thyroid cancer, thyroid nodules, and other complex thyroid disorders. Institutional Review Board approval and patiental informed consent were not required by the institutions for retrospective studies involving the anonymous review of medical records of patients followed at those institutions.

We collected data from patients aged $<18$ years with thyroid nodules diagnosed by physical examination and thyroid ultrasonography and with a histological diagnosis when submitted to surgery or a cytological diagnosis when submitted to fine-needle aspiration biopsy (FNAB). Patients submitted to FNAB but not to surgery because of benign cytology were followed for at least 1 year, with clinical and echographic evaluation every 6 months to further substantiate the benign nature of the nodule. Inclusion criteria were: (1) largest nodule diameter at least $1 \mathrm{~cm}$ and (2) serum TSH and free thyroxine levels measured within the 3 months before FNAB or surgery. The referring clinicians were asked to apply the following exclusion criteria: (1) cases treated for any other childhood cancer or exposed to radiation before the diagnosis of thyroid nodules ( $\mathrm{n}=32)$; (2) cases with autoimmune thyroiditis confirmed by thyroid antibody detection or an ultrasound pattern consistent with thyroiditis (inhomogenous and hypoechogenic) ( $\mathrm{n}=79)$; (3) cases in which levothyroxine was administered before nodule diagnosis $(\mathrm{n}=11)$; (4) cases with hyperthyroidism (defined as TSH $<0.4 \mathrm{mU} / \mathrm{L}$ ) or under methimazole/propylthiouracil treatment $(\mathrm{n}=4)$; (5) cases with hypothyroidism (defined as low serum free thyroxine concentrations with a concomitant rise in TSH) $(n=9)$; and (6) cases with a definite histological/cytological diagnosis of thyroid abscess, medullary thyroid cancer, or a rare thyroid histotype (eg, Hurtle-cell adenoma/carcinoma) $(\mathrm{n}=6)$.

Overall, 125 patients ( 105 females, 20 males) were included in this study. The cytological results yielded by FNAB were classified according to accepted guidelines. ${ }^{23,24}$

Body mass index (BMI) was defined as weight in kilograms divided by the square of height in meters. Published Italian standards for sex- and age-specific BMI percentiles were used to classify patients aged 2-18 years as overweight (85th-95th percentile) or obese ( $>95$ th percentile) and to calculate the respective BMI SDS. ${ }^{25}$ Patients aged $<2$ years with weight-for-length $>95$ th percentile were classified as obese.

Serum TSH concentration was measured by highly specific chemiluminescent immunoassays (Roche Diagnostics,
Manheim, Germany) in the laboratories of the various centers involved in the study, with intra-assay and interassay variations $<10 \%$. TSH reference values were $0.40-4.40 \mathrm{mU} / \mathrm{L}$ in all 9 laboratories.

Continuous variables are expressed as mean \pm SD (median, range). The Kolmogorov-Smirnov and Shapiro-Wilk tests were used to assess the parametric or nonparametric distribution of the numerical variables. The Student $t$ test and Wilcoxon and Mann-Whitney tests were used to check between-group differences in variables with a normal distribution and in variables with a skewed distribution, respectively. Pearson correlation coefficients were applied to check univariate associations. The $\chi^{2}$ test and Fisher exact test were used to assess the distribution of cathegorical variables. Binary logistic regression analysis was used to evaluate the independent influence of factors on the final diagnostic outcome (benign vs malignant), including largest nodule diameter, number of nodules (solitary nodules vs multinodular thyroid disease), age, sex, and serum TSH concentration at the time of FNAB.

Calculations were considered statistically significant at a $P$ value $<.05$. SPSS version 15.0 (IBM, Armonk, New York) was used for all statistical analyses.

\section{Results}

Of the 125 patients in our study cohort, 57 were submitted to surgery based on an FNAB result indicative of malignant or suspicious nodule or despite a benign cytology, clinical/echographic features suggestive of a malignancy (eg, palpable lymph nodes, microcalcifications, intranodular blood flow, ultrasonography-detected lymph node alterations, hypoechogenicity, irregular margins). Cytology was benign in 86 patients (18 who underwent surgery with a final diagnosis of goitrous nodule), malignant in 24 patients (all with histologically confirmed papillary cancer), suspicious in 15 patients (all who underwent surgery, 2 with a final diagnosis of follicular carcinoma, 6 with follicular adenoma, and 7 with benign goitrous nodule). Overall, 26 patients (20.8\%) were diagnosed with malignant thyroid nodules based on histology, 24 with papillary carcinoma and 2 with follicular carcinoma. The other 31 patients who underwent surgery received a final diagnosis of benign thyroid nodules with histology demonstrating goitrous nodule $(\mathrm{n}=25)$ or follicular adenoma $(\mathrm{n}=6)$.

In 68 patients, surgery was not performed because the nodule was considered benign. These patients (all with benign FNAB findings) were followed for a mean of $2.3 \pm$ 1.6 years (median, 2.8 years; range, 1.3-6.2 years) with clinical, laboratory, and echographic evaluation every 6 months. Over the follow-up period, no nodule developed suspicious features for malignancy, and thus none of these patients underwent surgery.

Concordance between cytology and histology was seen in all the patients with benign and malignant cytology, and considering the "suspicious" cytology results as malignant, 
Table I. Patient characteristics

\begin{tabular}{|c|c|c|c|}
\hline Characteristic & Benign nodule $(\mathrm{n}=99)$ & Malignant nodule $(n=26)$ & $P$ value \\
\hline Age at diagnosis, y, mean $\pm \mathrm{SD}$ (median, range) & $11.4 \pm 3.3(12.0,0.7-17.9)$ & $12.0 \pm 2.90(12.0,7.0-16.8)$ & .417 \\
\hline Females/males, $n$ & $83 / 16$ & $22 / 4$ & .989 \\
\hline Solitary/multinodular, n & $71 / 28$ & $22 / 4$ & .215 \\
\hline Largest nodule diameter at diagnosis, $\mathrm{cm}$, mean $\pm \mathrm{SD}$ (median, range) & $2.15 \pm 0.94(2.05,1.0-4.50)$ & $2.42 \pm 0.92(2.45,1.00-4.10)$ & .198 \\
\hline BMI SDS, mean \pm SD (range) & $0.16 \pm 1.09(-1.88$ to 3.36$)$ & $0.23 \pm 1.39(-1.67$ to 2.83$)$ & .768 \\
\hline Age at FNAB, y, mean \pm SD (median, range) & $11.9 \pm 3.45(12.4,0.7-17.9)$ & $12.3 \pm 3.09(12.4,7.0-17.8)$ & .552 \\
\hline Serum TSH concentration, mU/L, mean \pm SD (median, range) & $1.64 \pm 0.99(1.40,0.40-6.00)$ & $3.23 \pm 1.59(2.85,1.40-8.40)$ & $<.001$ \\
\hline
\end{tabular}

we had 13 false-positive results (all "suspicious"), for an overall sensitivity of $100 \%$, specificity of $58 \%$, and diagnostic accuracy of $77 \%$. Of the 125 patients, 26 had a differentiated thyroid cancer and 99 had benign nodules (Table I).

Overall, the mean serum TSH concentration was $2.01 \pm 1.30$ $\mathrm{mU} / \mathrm{L}$ (median, $1.60 \mathrm{mU} / \mathrm{L}$; range, $0.40-8.40 \mathrm{mU} / \mathrm{L}$ ). The distribution of serum TSH concentrations followed a tight symmetrical Gaussian curve, peaking at a median value of $1.60 \mathrm{mU} / \mathrm{L}$ (Figure 1). The mean serum TSH concentration was $3.23 \pm$ $1.59 \mathrm{mU} / \mathrm{L}$ (median, $2.85 \mathrm{mU} / \mathrm{L}$; range, $1.40-8.4 \mathrm{mU} / \mathrm{L}$ ) in the patients with thyroid cancer and $1.64 \pm 0.99 \mathrm{mU} / \mathrm{L}$ (median, $1.40 \mathrm{mU} / \mathrm{L}$; range, $0.41-6.00 \mathrm{mU} / \mathrm{L}$ ) $\mathrm{mU} / \mathrm{L}$ in those with benign thyroid nodules, with a significant difference between the 2 groups $(P<.001)$. There was no sex-based difference in the malignancy rate; malignancy was found in 4 of the 20 males $(20.0 \%$; 3 papillary cancers and 1 follicular cancer) vs 22 of the 105 females $(20.9 \%$; 21 papillary and 1 follicular). Mean serum TSH concentration was significantly lower in males compared with females $(1.41 \pm 0.67 \mathrm{mU} / \mathrm{L}$ vs $2.13 \pm 1.37 \mathrm{mU} / \mathrm{L} ; P<.001)$. Males and females showed no significant differences in age at nodule diagnosis, age at FNAB, BMI SDS, uninodular/multinodular ratio, or largest nodule diameter. Moreover, there were no significant differences between patients with solitary nodules and those with multinodular thyroid disease. Mean serum TSH concentrations were comparable in obese $(n=5)$ and overweight patients $(\mathrm{n}=28)$ and patients with normal BMI $(1.84 \pm 1.12 \mathrm{mU} / \mathrm{L}$ vs $2.07 \pm 1.36 \mathrm{mU} / \mathrm{L} ; P=.369)$. No correlation was found between serum TSH concentration and the largest nodule diameter, BMI SDS, patient age at nodule diagnosis and at FNAB, or number of nodules, nor were any correlations found when evaluating the patients with benign nodules and those with malignant nodules separately.

Binary logistic regression analyses including sex, largest nodule diameter, age at diagnosis, solitary ultrasound, uninodular or multinodular disease, and serum TSH concentration were performed to identify independent risk factors predictive of thyroid malignancy. Significantly increased ORs were found only for serum TSH concentration $(P<$ $.001)$; none of the other factors was found to independently predict the presence of malignancy (Table II).

The 125 patients were divided into 5 groups of 25 patients each based on serum TSH quintile: $0.40-1.00 \mathrm{mU} /$ $\mathrm{L}, 1.01-1.50 \mathrm{mU} / \mathrm{L}, 1.51-1.80 \mathrm{mU} / \mathrm{L}, 1.81-2.80 \mathrm{mU} / \mathrm{L}$, and $>2.80 \mathrm{mU} / \mathrm{L}$. The prevalence of malignancy increased significantly $\left(P<.001, \chi^{2}\right.$ test $)$ with increasing TSH concentration, with respective rates of $0 \%, 4 \%, 16 \%, 32 \%$, and $52 \%$ in the 5 quintiles (Figure 2). The OR of

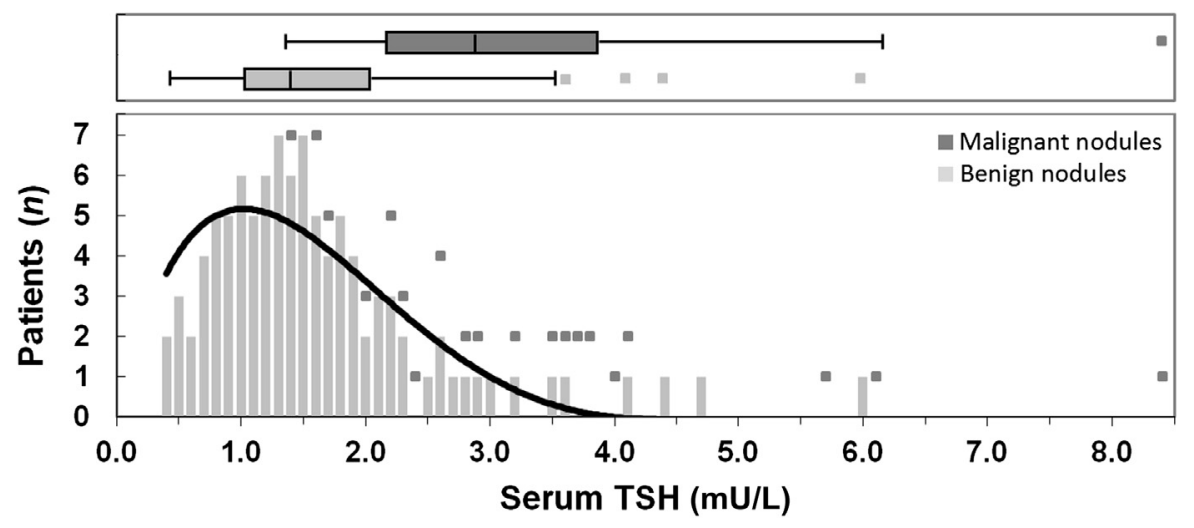

Figure 1. Distribution of serum TSH concentrations in the study cohort. The light-gray bars represent patients with benign thyroid nodules, and the dark-gray squares represent patients with thyroid cancer. The distribution roughly follows a normal distribution with a median serum TSH value of $1.60 \mathrm{mU} / \mathrm{L}$. The box-and-whisker plot summarizes the distribution, with the 25th75th percentiles represented by boxes, the median by a vertical line, the range by whiskers, and the outliers by squares. The median serum TSH concentration in benign nodules was $1.40 \mathrm{mU} / \mathrm{L}$, and the cases with thyroid cancer were skewed rightward, all with serum TSH concentrations exceeding this value. 
Table II. Independent predictors of the diagnosis of thyroid malignancy in binary logistic regression analysis

\begin{tabular}{lccr}
\hline \multicolumn{1}{c}{ Variable } & aOR & 95\% CI & P value \\
\hline Sex & 0.337 & $0.078-1.452$ & .144 \\
Age at diagnosis & 1.127 & $0.941-1.350$ & .194 \\
Largest nodule diameter, cm & 1.153 & $0.645-2.059$ & .631 \\
Solitary vs multinodular & 0.135 & $0.013-1.415$ & .095 \\
Serum TSH & 3.133 & $1.888-5.201$ & $<.001$ \\
\hline
\end{tabular}

malignant versus benign nodules was calculated for the thresholds of 1.50, 1.80, and $2.80 \mathrm{mU} / \mathrm{L}$ (Figure 2) and the comparison of patients with a serum TSH above versus below the median serum TSH concentration of the cohort $(1.6 \mathrm{mU} / \mathrm{L})$, which resulted in an OR of 16.2. Positive and negative predictive values were calculated for the serum TSH thresholds of 1.60 and $2.80 \mathrm{mU} / \mathrm{L}$ and found to be $36.4 \%$ and $96.6 \%$, respectively, for the former and $53.8 \%$ and $87.8 \%$ for the latter. The highest diagnostic accuracy $(87.1 \%)$ was found at the $2.80-\mathrm{mU} / \mathrm{L}$ threshold.

All of the foregoing analyses (comparison of means between paired groups, binary logistic regression, and correlations) were repeated including only the patients with available histological results (ie, those submitted to surgery; $\mathrm{n}=57$ ), yielding similar results. The results were also similar when the 2 cases of differentiated thyroid cancer of follicular

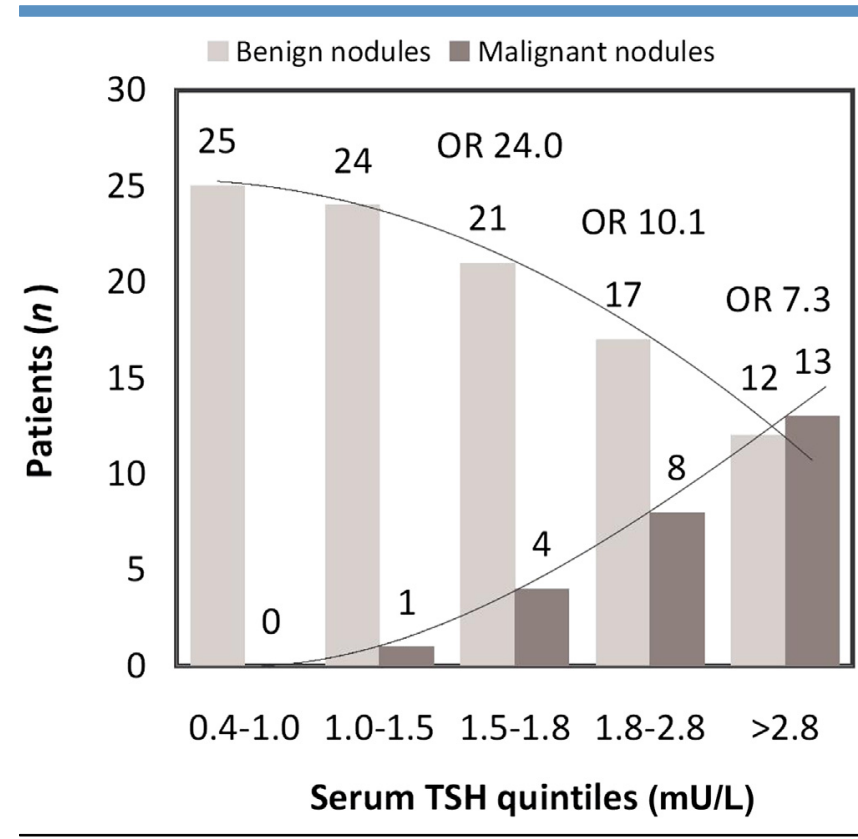

Figure 2. Prevalence of thyroid malignant nodules (dark gray) over benign nodules (light gray) according to the serum TSH concentration measured at diagnosis. The 125 patients were divided into serum TSH quintiles in which the observed malignancy rate progressed significantly $(0 \%, 4 \%, 16 \%, 32 \%$, and $52 \%$, respectively, $P<.001, \chi^{2}$ test). ORs for the 3 highest thresholds are reported. type, with serum TSH concentrations of $2.00 \mathrm{mU} / \mathrm{L}$ and 2.23 $\mathrm{mU} / \mathrm{L}$, were excluded from the analyses.

\section{Discussion}

Serum TSH determination at thyroid nodule presentation is instrumental in the diagnostic evaluation of these nodules in both adults and children. ${ }^{21-23}$ Recent studies of adults with thyroid nodules have established a correlation between serum TSH concentrations in the upper one-half of the normal range and an increased likelihood of differentiated thyroid carcinoma, ${ }^{13,14}$ suggesting that TSH concentration can provide an additional clue to malignancy. We designed the present study to evaluate this possibility in the pediatric population, in which data are scanty. ${ }^{17}$

Consistent with previously published data, we observed a striking right-skewed distribution of serum TSH concentrations in children and adolescents with differentiated thyroid cancer compared with those with benign thyroid nodules. Although most laboratory reference ranges define the normal range of serum TSH concentration as $0.4-4.4 \mathrm{mU} / \mathrm{L}$, large population studies have demonstrated a median TSH concentration of approximately $1.4-1.8 \mathrm{mU} / \mathrm{L},{ }^{26-28}$ suggesting that a more realistic upper limit may be 2.5-3.0 mU/L. Given the limitations of pediatric studies and the small size of our cohort in the present study, our data are consistent with these observations. The distribution of serum TSH concentrations in the children and adolescents with benign nodules loosely followed a Gaussian curve, peaking at approximately 1.50 $\mathrm{mU} / \mathrm{L}$, with some outliers in the right tail. Serum TSH concentrations of the patients with malignant nodules were clearly scattered on the right part of the curve, falling mostly in the right tail. In fact, all of the serum TSH values in the patients with thyroid carcinomas exceeded the median serum TSH value of the patients with benign nodules. The mean serum TSH concentration in the patients with thyroid carcinomas was almost double that in the patients with benign nodules $(3.2 \mathrm{mU} / \mathrm{L}$ vs $1.6 \mathrm{mU} / \mathrm{L})$, as significant difference.

Dividing our cohort into quintiles based on serum TSH concentration revealed an significantly increased prevalence of thyroid cancer with increasing TSH concentration. Thyroid cancer was absent in the patients with a serum TSH value of $0.40-1.0 \mathrm{mU} / \mathrm{L}$, whereas its prevalence exceeded $50 \%$ in those with a serum TSH value $>2.8 \mathrm{mU} / \mathrm{L}$. The odds of having a malignant nodule increased progressively from the first to fifth quintiles, with the patients with a serum TSH concentration above the median value of our cohort $(1.60 \mathrm{mU} / \mathrm{L})$ having an estimated $\sim 16$-fold increase in cancer likelihood compared with those with a serum TSH concentration below this threshold. Finally, by multivariate analysis, we identified serum TSH concentration as an independent predictor of malignancy in our cohort, and determined that none of the other covariates evaluated had an effect on final patient outcomes.

Unlike Chiu et $\mathrm{al}^{17}$ and other investigators who evaluated adults, ${ }^{14}$ we decided to exclude patients with autoimmune thyroiditis and those previously treated with radiotherapy 
for other tumors. In these 2 conditions, the prevalence and etiology of thyroid nodules likely do not reflect those of the general population, and thus we excluded these 2 conditions to avoid possible confounding and bias. Moreover, hypothyroidism (with consequent increased serum TSH) is commonly seen in both of these conditions.

Similarly, we decided to include only cases with papillary or follicular thyroid cancer because these are the 2 malignant histotypes most often seen in the pediatric population, and also because papillary and follicular thyroid cancer are well differentiated and thus expected to be highly TSHresponsive compared with other, rarer histotypes. We also checked for overweight/obesity as potential confounders given the possible association with elevated serum TSH concentration, ${ }^{29}$ but found no correlation.

Our study has several limitations that should be acknowledged. Given the study's retrospective design and the fact that thyroid nodules were mostly detected clinically, some small and nonpalpable nodules possibly harboring carcinoma might have been missed. Moreover, because thyroid nodules and cancer is relatively rare in children compared with adults, this was a multicenter study, and thus was potentially biased by differences in the clinical management of patients followed at the various centers. Furthermore, serum TSH determination and cytological/histological evaluation were not performed in a centralized manner. Finally, in approximately one-half of the patients, the benign nature of the nodules was not confirmed histologically but rather was based on a benign cytology plus a minimum of 1 year of follow-up. However, FNAB is the recognized standard for evaluating thyroid nodules in both adults and children, with proven high sensitivity for detecting malignancies. ${ }^{30-33}$ Thus, we believe that considering those cases with a negative FNAB as benign is a reasonable approach and is not likely to have a significant impact on our results. Moreover, a separate statistical analysis including only patients with histological results available yielded comparable results.

In conclusion, in medical practice, clinical, laboratory, and echographic evaluations are used to determine the likelihood of malignancy in pediatric patients with thyroid nodules and to determine the need to refer for FNAB. Palpable lymph nodes, microcalcifications, lymph node abnormalities, and increased intranodular vascularization on ultrasonography are suggestive of malignancy. ${ }^{21}$ Our results suggest that serum TSH concentration has a role as a predictor of the likelihood of thyroid cancer in pediatric patients with thyroid nodules and can be used in clinical practice to increase the suspicion for a malignant etiology. Although serum TSH fluctuations fall within the reference range in most patients with thyroid nodules, those with malignant nodules are more likely to have a serum TSH concentration in the upper-normal range, and patients with a serum TSH value $>2.8 \mathrm{mU} / \mathrm{L}$ are at clearly increased risk for cancer. Thus, serum TSH measurement should be added to the repertoire of test and other variables used in the clinical setting to determine whether to submit patients with thyroid nodules to further investigation by FNAB. Cytology remains the gold standard for predicting malignancy and is more reliable than any biochemical marker identified to date.

Submitted for publication Dec 31, 2012; last revision received Jun 17, 2013; accepted Jul 1, 2013.

Reprint requests: Alessandro Mussa, MD, PhD, Department of Pediatrics, University of Torino, Piazza Polonia 94, 10126 Torino, Italy. E-mail: alessandro. mussa@unito.it

\section{References}

1. Carayon P, Thomas-Morvan C, Castanas E, Tubiana M. Human thyroid cancer: membrane thyrotropin binding and adenylate cyclase activity. J Clin Endocrinol Metab 1980;51:915-20.

2. García-Jiménez C, Santisteban P. TSH signalling and cancer. Arq Bras Endocrinol Metabol 2007;51:654-71.

3. Kim CS, Zhu X. Lessons from mouse models of thyroid cancer. Thyroid 2009;19:1317-31.

4. Zhu XG, Cheng SY. Modeling thyroid cancer in the mouse. Horm Metab Res 2009;41:488-99.

5. Nikiforov YE. Genetic alterations involved in the transition from welldifferentiated to poorly differentiated and anaplastic thyroid carcinomas. Endocr Pathol 2004;15:319-27.

6. Boelaert K, Horacek J, Holder RL, Watkinson JC, Sheppard MC, Franklyn JA. Serum thyrotropin concentration as a novel predictor of malignancy in thyroid nodules investigated by fine-needle aspiration. J Clin Endocrinol Metab 2006;91:4295-301.

7. Fiore E, Rago T, Provenzale MA, Scutari M, Ugolini C, Basolo F, et al. L-thyroxine-treated patients with nodular goiter have lower serum TSH and lower frequency of papillary thyroid cancer: results of a crosssectional study on 27914 patients. Endocr Relat Cancer 2010;17:231-9.

8. Pujol P, Daures JP, Nsakala N, Baldet L, Bringer J, Jaffiol C. Degree of thyrotropin suppression as a prognostic determinant in differentiated thyroid cancer. J Clin Endocrinol Metab 1996;81:4318-23.

9. Biondi B, Cooper DS. Benefits of thyrotropin suppression versus the risks of adverse effects in differentiated thyroid cancer. Thyroid 2010;20:135-46.

10. Corrias A, Mussa A, Wasniewska M, Segni M, Cassio A, Salerno M, et al. Levothyroxine treatment in pediatric benign thyroid nodules. Horm Res Paediatr 2011;75:246-51.

11. Papini E, Petrucci L, Guglielmi R, Panunzi C, Rinaldi R, Bacci V, et al. Long-term changes in nodular goiter: a 5 -year prospective randomized trial of levothyroxine suppressive therapy for benign cold thyroid nodules. J Clin Endocrinol Metab 1998;83:780-3.

12. Papini E, Bacci V, Panunzi C, Pacella CM, Fabbrini R, Bizzarri G, et al. A prospective randomized trial of levothyroxine suppressive therapy for solitary thyroid nodules. Clin Endocrinol (Oxf) 1993;38:507-13.

13. McLeod DS, Watters KF, Carpenter AD, Ladenson PW, Cooper DS, Ding EL. Thyrotropin and thyroid cancer diagnosis: a systematic review and dose-response meta-analysis. J Clin Endocrinol Metab 2012;97: 2682-92.

14. Fiore E, Vitti P. Serum TSH and risk of papillary thyroid cancer in nodular thyroid disease. J Clin Endocrinol Metab 2012;97:1134-45.

15. Niedziela M. Pathogenesis, diagnosis and management of thyroid nodules in children. Endocr Relat Cancer 2006;13:427-53.

16. Wiersinga WM. Management of thyroid nodules in children and adolescents. Hormones (Athens) 2007;6:194-9.

17. Chiu HK, Sanda S, Fechner PY, Pihoker C. Correlation of TSH with the risk of paediatric thyroid carcinoma. Clin Endocrinol (Oxf) 2012;77:316-22.

18. Hegedüs L. Clinical practice: the thyroid nodule. N Engl J Med 2004;351: 1764-71.

19. Frates MC, Benson CB, Doubilet PM, Kunreuther E, Contreras M, Cibas ES, et al. Prevalence and distribution of carcinoma in patients with solitary and multiple thyroid nodules on sonography. J Clin Endocrinol Metab 2006;91:3411-7.

20. Corrias A, Mussa A. Thyroid nodules in pediatrics: which ones can be left alone, which ones must be investigated, when and how. J Clin Res Pediatr Endocrinol 2013;5:S57-69. 
21. Corrias A, Mussa A, Baronio F, Arrigo T, Salerno M, Segni M, et al. Diagnostic features of thyroid nodules in pediatrics. Arch Pediatr Adolesc Med 2010;164:714-9.

22. Corrias A, Cassio A, Weber G, Mussa A, Wasniewska M, Rapa A, et al. Thyroid nodules and cancer in children and adolescents affected by autoimmune thyroiditis. Arch Pediatr Adolesc Med 2008;162:526-31.

23. Cooper DS, Doherty GM, Haugen BR, Kloos RT, Lee SL, Mandel SJ, et al. American Thyroid Association Guidelines Taskforce. Management guidelines for patients with thyroid nodules and differentiated thyroid cancer. Thyroid 2006;16:109-42.

24. Cooper DS, Doherty GM, Haugen BR, Kloos RT, Lee SL, Mandel SJ, et al. Revised American Thyroid Association management guidelines for patients with thyroid nodules and differentiated thyroid cancer. Thyroid 2009;19:1167-214.

25. Cacciari E, Milani S, Balsamo A, Spada E, Bona G, Cavallo L, et al. Italian cross-sectional growth charts for height, weight and BMI (2 to $20 \mathrm{yr}$ ). J Endocrinol Invest 2006;29:581-93.

26. Hollowell JG, Staehling NW, Flanders WD, Hannon WH, Gunter EW, Spencer CA, et al. Serum TSH, T(4), and thyroid antibodies in the United States population (1988 to 1994): National Health and Nutrition Examination Survey (NHANES III). J Clin Endocrinol Metab 2002;87: 489-99.
27. Kratzsch J, Fiedler GM, Leichtle A, Brügel M, Buchbinder S, Otto L, et al. New reference intervals for thyrotropin and thyroid hormones based on National Academy of Clinical Biochemistry criteria and regular ultrasonography of the thyroid. Clin Chem 2005;51:1480-6.

28. Wartofsky L, Dickey RA. The evidence for a narrower thyrotropin reference range is compelling. J Clin Endocrinol Metab 2005;90:5483-8.

29. Radetti G, Kleon W, Buzi F, Crivellaro C, Pappalardo L, di Iorgi N, et al. Thyroid function and structure are affected in childhood obesity. J Clin Endocrinol Metab 2008;93:4749-54.

30. Corrias A, Einaudi S, Chiorboli E, Weber G, Crinò A, Andreo M, et al. Accuracy of fine-needle aspiration biopsy of thyroid nodules in detecting malignancy in childhood: comparison with conventional clinical, laboratory, and imaging approaches. J Clin Endocrinol Metab 2001;86: 4644-8.

31. Kaur J, Srinivasan R, Arora SK, Rajwanshi A, Saikia UN, Dutta P, et al. Fine-needle aspiration in the evaluation of thyroid lesions in children. Diagn Cytopathol 2012;40:E33-7.

32. Kapila K, Pathan SK, George SS, Haji BE, Das DK, Qadan LR. Fine-needle aspiration cytology of the thyroid in children and adolescents: experience with 792 aspirates. Acta Cytol 2010;54:569-74.

33. Moslavac S, Matesa N, Kusić Z. Thyroid fine-needle aspiration cytology in children and adolescents. Coll Antropol 2010;34:197-200. 